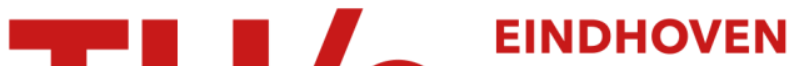 UNIVERSITY OF TECHNOLOGY
}

\section{Adaptive thermal comfort in primary school classrooms : creating and validating PMV-based comfort charts}

Citation for published version (APA):

Mors, ter, S., Hensen, J. L. M., Loomans, M. G. L. C., \& Boerstra, A. C. (2011). Adaptive thermal comfort in primary school classrooms : creating and validating PMV-based comfort charts. Building and Environment, 46(12), 2454-2461. https://doi.org/10.1016/j.buildenv.2011.05.025

DOI:

10.1016/j.buildenv.2011.05.025

Document status and date:

Published: 01/01/2011

Document Version:

Accepted manuscript including changes made at the peer-review stage

Please check the document version of this publication:

- A submitted manuscript is the version of the article upon submission and before peer-review. There can be important differences between the submitted version and the official published version of record. People interested in the research are advised to contact the author for the final version of the publication, or visit the $\mathrm{DOI}$ to the publisher's website.

- The final author version and the galley proof are versions of the publication after peer review.

- The final published version features the final layout of the paper including the volume, issue and page numbers.

Link to publication

\section{General rights}

Copyright and moral rights for the publications made accessible in the public portal are retained by the authors and/or other copyright owners and it is a condition of accessing publications that users recognise and abide by the legal requirements associated with these rights.

- Users may download and print one copy of any publication from the public portal for the purpose of private study or research.

- You may not further distribute the material or use it for any profit-making activity or commercial gain

- You may freely distribute the URL identifying the publication in the public portal.

If the publication is distributed under the terms of Article 25fa of the Dutch Copyright Act, indicated by the "Taverne" license above, please follow below link for the End User Agreement:

www.tue.nl/taverne

Take down policy

If you believe that this document breaches copyright please contact us at:

openaccess@tue.nl

providing details and we will investigate your claim. 


\title{
Adaptive thermal comfort in primary school classrooms: Creating and validating PMV-based comfort charts
}

\author{
Sander ter Mors ${ }^{\mathrm{a}}$, Jan L.M. Hensen ${ }^{\mathrm{a}}$, Marcel Loomans ${ }^{\mathrm{a}, *}$, Atze Boerstra $^{\mathrm{b}, \mathrm{a}}$ \\ ${ }^{a}$ Eindhoven University of Technology, Eindhoven, Netherlands \\ ${ }^{\mathrm{b}}$ BBA Indoor Environmental Consultancy, Rotterdam, Netherlands
}

\section{Abstract}

In this research the thermal comfort and thermal comfort parameters for children in primary school classrooms has been investigated. Actual thermal sensation and clothing insulation of children (age 9-11) in non-air-conditioned classrooms in three different schools in the Netherlands have been obtained. Results are available for a total of 24 days, covering winter, spring and summer conditions (year 2010). Questionnaires have been applied to obtain the actual thermal sensation and clothing insulation in the morning and afternoon of regular school days. In this period physical parameters (temperature, relative humidity, etc.) were recorded as well in order to derive the PMV.

The results show that children adapt clothing during the year from mean values around 0.9 clo in winter to 0.3 clo in summer, with the largest changes occurring in the mid-season. There is a small difference in clothing adaptation between male and female children, with the females showing more adaptation.

Comparison of the actual mean vote with the calculated PMV, based on the measured data, indicates a clear difference. The conclusion is that the PMV model does not predict the thermal sensation of these children accurately; it underestimates the mean thermal sensation up to 1.5 scale point.

When the actual thermal sensation votes are compared to comfort predictions based on adaptive temperature limits it shows that children prefer lower temperatures than predicted by these methods.

Keywords: Predicted Mean Vote, Clothing Insulation, Adaptive Thermal Comfort, Primary School Classroom, Assessment Methods

\section{Introduction}

The Adaptive Temperature Limits (ATL) [1] method which is used in the Netherlands was developed for naturally ventilated office buildings. It shows the required operative temperatures as function of a weighted running mean of the exterior temperature; this is a very easy-to-understand representation of thermal comfort criteria. Another method to predict thermal comfort is Fanger's Predicted Mean Vote (PMV) [2]. Earlier research by van der Linden et al [3] indicated that the PMV method, with correct input, can lead to similar predictions as the ATL method, for thermal comfort in a moderate climate like the Netherlands. With correct input is meant: sufficient detail on personal and environmental parameters. The advantage of the PMV-method is that its input can be adjusted to the specific situation to be evaluated, so the range of buildings it can be applied to is broader.

In order to investigate this assumption, this research addresses thermal comfort evaluation for primary school classrooms in the Netherlands. The indoor environment in classrooms can have a large effect on comfort, health and learning performance [4]. The aim is to assess whether the PMV method can be used to improve accuracy of thermal comfort predictions for non-airconditioned primary school class rooms when the input conditions more accurately represent realistic conditions as was assumed for naturally ventilated offices in [3]. Specific attention was given to the clothing insulation for children, and adaptation of clothing during the year.

Thermal comfort is defined by ASHRAE [5] as 'that condition of mind which expresses satisfaction with the thermal environment and is assessed by subjective evaluation'. The subjective evaluation of thermal comfort is influenced by the thermal environment and personal factors influencing the heat transfer with this environment, but also by psychological factors influencing the condition of mind directly. All these factors in thermal comfort can be altered by behavioural, physiological or psychological adaptation.

Many thermal comfort criteria and predictions are based on the PMV as introduced by Fanger [2] and presented in ISO 7730:2005 [6]. This comfort equation can be used to calculate the PMV. This predicted thermal sensation can be transferred to the predicted thermal comfort in the form of Predicted Percentage Dissatisfied (PPD), which is the predicted percentage of people in a large group that will be dissatisfied at a PMV value. A PMV of 0 does not mean every individual has thermal neutrality, i.e. the PPD is not zero.

\footnotetext{
* Corresponding author: M.G.L.C.Loomans@tue.nl; P.O.Box 513, VRT 6.23; NL-5600 MB Eindhoven; The Netherlands; tel.+31 402474651 ; fax +31402478595.
} 
Fanger's comfort equation is derived from extensive climate chamber research. The responses of over a thousand European and American subjects to the thermal conditions in a well-controlled environment were used to expand this equation into the PMV model. This equation and the PMV model are intended for use in the design of HVAC systems.

The calculation of the PMV takes into account the thermo physiological properties of humans and their thermal balance with the environment. On a personal level this includes the activity level and clothing insulation. The thermal environment is determined by the variables air temperature, mean radiant temperature, relative humidity, and air velocity. Physiological variation and psychological effects are not taken into account in the PMV model. In [7] it is shown that for HVAC buildings this method can accurately predict comfort temperatures, but for free-running buildings the thermal sensation is underestimated in winter and overestimated in summer. Psychological adaptation is given as the most likely reason for this divergence.

ISO 7730 [6] gives validity intervals for the PMV variables, and when one or more of the variables are outside this range the results from the model are no longer considered reliable. These validity intervals are discussed by Humphreys and Nicol [8] who conclude that the ranges for valid use of PMV are much narrower. They also conclude that the resulting bias in PMV outcome can be very misleading when assessing thermal comfort among people in everyday conditions, and state that it could be useful to reconsider the relations between metabolic rate, skin temperature and sweat production for comfortable conditions.

The relation between PMV and PPD is also subject to discussion. In [9], results from various climate chamber and field researches are shown to vary (strongly) from Fanger's PMV/PPD relation. Corgnati et al [10] found a trend for thermal preference from slightly warm environments in the winter period to neutral environments in the temperate season.

The clothing insulation and metabolic heat production can be estimated, but practical methods to do this are not accurate and affect the uncertainty in the final thermal sensation prediction to a large extent. Improving the methods to determine clothing insulation and metabolism can improve accuracy and quality of PMV based predictions [9]. Clothing insulation determination methods based on tables stating insulating values for various garments can vary $20 \%$ in results [11], also influencing the PMV outcome.

Havenith et al [12] investigated methods to determine metabolism and clothing insulation. One of their conclusions is that posture and air speed can cause a reduction of clothing vapour resistance, and the impact this has on comfort limits in terms of skin wettedness cannot be neglected. Furthermore they conclude that to improve metabolic rate estimation for activities below 2 met by using ISO 8996 [13] more data and detail is needed, and that the current methods described in ISO 8996 are not sufficiently accurate to estimate PMV within 0.3 scale points.

Besides all critique on the PMV model and its performance in predicting thermal comfort, many times no alternatives for field use are given. For some specific regions or application ranges, [8] and [14] do offer (methods to implement) empirical improvements to the PMV model. In [9] a variety of PMV model adjustment and improvement studies are described. In [15], Fanger and Toftum introduce the expectancy factor ' $e$ ' as addition to the PMV model, specifically for use in non-air-conditioned buildings in warm climates. In this situation the expectancy of indoor climate is low, so higher temperatures are accepted and not always considered uncomfortable. The value of the expectancy factor will always be in the range $0.5-1.0$ and is determined by location and frequency of warm periods. The calculated PMV is multiplied by the expectancy factor, which results in the new PMV. Since in the Netherlands warm periods are not common the expectancy factor will be 0.9-1.0. A value of 1.0 would mean that the calculated PMV will not change, so the expectancy factor has little or no influence in the Netherlands.

In the original thermal comfort research by Fanger, there were no children included in the climate chamber tests. This lead Fanger to state that more research would be required to test if the comfort equation could be applied to (young) children [2]. The relations between metabolic rate, skin temperature, sweat production and thermal sensation or thermal comfort which are the base of the PMV model might not be the same for children.

According to Humphreys [16], children seem to be a bit less sensitive to temperature change than adults, and there is also a larger variation among the responses of children. The explanation for these observations is the higher normal activity level of children, and the fact that there is a large variety in the activity level during education. Humphrey's research also showed that the children did not change their clothing during the day. The average clothing value changed only on the longer term, but the room temperature and mean thermal sensation did change during the day.

Besides the possible difference in the relation between metabolic rate and thermal sensation, the metabolic rate itself is also different between children and adults. This is shown by Havenith [17], who investigated the metabolic rate and clothing insulation for various classroom types and age groups. From this research it can be concluded that the metabolism for 9-11 year old children varies from 52 to 64 Watts per $\mathrm{m}^{2}$ body surface for various sedentary classroom activities. For adults this would be higher, around $70-100 \mathrm{~W} / \mathrm{m}^{2}$ when estimated by ISO 8996:2004 as 'clerical work' [13]. ISO 7730:2005 [6] estimates sedentary office activity metabolism at 1.2 met $\left(1 \mathrm{met}=58.2 \mathrm{~W} / \mathrm{m}^{2}\right)$, which is equal to the ISO 8890 estimation lower limit of 70 $\mathrm{W} / \mathrm{m}^{2}$.

A different approach to determine the metabolic heat production for children is presented by Parsons [18]. Here he states that, as a first approximation, the data from ISO 8996:1990 (this version of the standard has been replaced by [13]) may be used 
with appropriate correction for reduced mass and surface areas of the body. It is however not specified how this correction should be applied.

As an alternative to the PMV method, NEN-EN 15251 [19] and ASHRAE Standard 55-2004 [5] are the most widely used adaptive assessment charts for thermal comfort. These adaptive methods do not base their predictions on the heat balance but instead use field research data for thermal sensation, preference and acceptance. Even though the two seem similar, there are four important differences which are discussed in detail by Nicol and Humphreys [20]: They are derived from different databases; the building type they apply to is not the same; the method used to determine neutral temperature is different; and the exterior temperature variable used is different.

ISSO 74 [1] is a Dutch adaptive guideline which introduces another building classification and exterior temperature variable. These limits are based on and extended from [7], on which the ASHRAE Standard 55-2004 is also based. Since (practically) all buildings which are free-running in summer do have active heating for colder seasons, ISSO 74 combines the adaptive limits for the free-running season with HVAC limits for the heating season. For external climates below $\theta \mathrm{e}$, ref $=10-12^{\circ} \mathrm{C}$ ( $\theta$ e, ref: 4 day weighted running mean temperature) the limits for all building types are equal, only the upper temperature limits for higher temperatures differs. ISSO 89 [21] is a guideline for the indoor climate in schools, and the thermal comfort limits shown here are a simplified version of the ISSO 74 adaptive limits to make this guideline better understandable for primary school boards.

The various exterior temperature definitions used in the comfort standards mentioned are shown and explained in Table 1.

Table 1: Variables to define external climate as used in various standards

\begin{tabular}{lll}
\hline Standard & $\begin{array}{l}\text { Exterior } \\
\text { Temperature } \\
\text { variable }\end{array}$ & Definition \\
\hline ASHRAE 55-1992 & ET $^{\star}$ & Mean daily outdoor effective temperature \\
\hline ASHRAE 55-2004 & $\mathrm{t}_{\mathrm{a}(\text { out }}$ & Monthly mean of daily min/max mean \\
\hline NEN-EN 15251 & $\theta_{\mathrm{rm}}$ & Weighted running mean of daily mean, excluding current day \\
\hline ISSO 74 & $\theta_{\mathrm{e}, \text { ref }}$ & 4 day weighted running mean of daily min/max mean, including current day \\
\hline ISSO 89 & $\theta_{b u}$ & Current external temperature \\
\hline
\end{tabular}

Earlier research [3] has shown that the PMV model, using correct input, can explain the adaptive limits from ISSO 74 [1]. The main aim of this research is to investigate if the Fanger-method can be used to develop 'simple' comfort charts, similar to the Adaptive Temperature Limits, but for non-office buildings and specifically a primary school classroom.

To achieve this all variables in the PMV method will be determined for this situation. The variables can be influenced by exterior climate, meaning the value will change during the year. Another possibility is change based on interior or local climate, changing the value during the day. Users can also adapt the personal factors which influence the heat balance in order to maintain personal thermal comfort. This adaptation can be physiological, psychological or behavioural. The focus in this project will be on behavioural adaptation, and specifically on the variable clothing insulation. This will show how children adapt their clothing with changing exterior climate during the year.

\section{Methods}

A field research was conducted in non-air-conditioned classrooms in three different schools located in Eindhoven, the Netherlands. In order to derive the PMV for the children (age 9-11) in these classrooms questionnaires were applied to obtain the activity level and clothing garments worn in the morning and afternoon of regular school days, and the physical parameters which influence the thermal sensation were recorded as well. This was done for a total of 24 days in three sessions, covering winter, spring and summer conditions (year 2010). Besides the data needed to determine the PMV, the actual thermal sensation and satisfaction were included in the questionnaires as well to obtain the subjective evaluation of thermal comfort. Thermal satisfaction was only included in the mid-season and summer measurements. Questions on thermal sensation were asked on a discrete seven-point (ASHRAE) scale, just as draught sensation (ranging from no draught at all experienced till seriously troubled). Thermal satisfaction was asked on a discrete two-point scale (acceptable/not-acceptable).

Clothing values were calculated using garment insulation values from ISO 7730 [6]. The aim was to keep the questionnaire easy-to-understand and concise. To do this, clothing which was not expected to be worn was excluded from the list. Also, for tshirts, vests and dresses three variants were included; sleeveless, short sleeve and long sleeve. When the clothing ensemble specified was not realistic, the data was disregarded. When minor clothing garments were missing (shoes, socks or underwear) this value was estimated. Data for the teachers was also recorded, but not used in the analysis. For the insulating value of the chair a value of $0.01 \mathrm{clo}\left(1 \mathrm{clo}=0.155 \mathrm{~m}^{2} \mathrm{~K} / \mathrm{W}\right)$ was applied since open wooden chairs were used in the classroom.

Metabolic rate was determined with classification according to activity, using ISO 7730 [6] instead of ISO 8996 [13] since the latter method would classify all school activities as 'low metabolic rate' without further distinction. Further distinction was possible by determining the metabolic rate in met, using the categories 'Seated, relaxed' (met=1.0), 'Sedentary activity' (met=1.2) and 'Standing, light activity' (met=1.6). This metabolic rate was corrected for the reduced surface area by multiplying it by $1.7 / 1.14$ [18]. The mean body surface area is $1.7 \mathrm{~m}^{2}$ for adults and $1.14 \mathrm{~m}^{2}$ for 10 year olds [22]. Reduced mass was not taken into account, external work for sedentary tasks and tasks with low activity can be estimated as $0 \mathrm{~W}$ [12]. This results in 
metabolic rate values of 86,104 or $139 \mathrm{~W} / \mathrm{m}^{2}$. For comparison of resulting thermal sensation predictions, the metabolism will also be changed to $60 \mathrm{~W} / \mathrm{m}^{2}$, estimated based on the data found by Havenith [17].

The three classrooms were located in buildings built in 2002, 1994 and 1964, and all located on the top floor of the building. All had centrally controlled heating by radiators and operable windows. The first school did have mechanical exhaust ventilation, but at a very low volume flow rate so operable windows were the main source of ventilation in all seasons. For the second school this was the case in winter and mid-season, but in summer the mechanical exhaust volume flow rate was set higher, windows were kept closed and a local cooling unit was placed in the classroom. Still the indoor climate showed a free-running temperature trend, so the influence of this cooling was minimal. The third school had only operable windows for ventilation.

In each classroom the physical parameters were recorded on a single central location. The air temperature $\left[ \pm 0.5^{\circ} \mathrm{C}\right.$ for $5-55^{\circ} \mathrm{C}$, $\pm 0.2^{\circ} \mathrm{C}$ at $\left.20^{\circ} \mathrm{C}\right]$, globe temperature $\left[ \pm 0.5^{\circ} \mathrm{C}\right.$ for $5-40^{\circ} \mathrm{C}, \pm 0.4^{\circ} \mathrm{C}$ at $\left.20^{\circ} \mathrm{C}\right]$, air humidity $[ \pm 2 \% \mathrm{RH}$ for $0-90 \%$ and air temperature $\left.10-40^{\circ} \mathrm{C}\right]$ and air velocity $[ \pm 0.02 \mathrm{~m} / \mathrm{s} \pm 1 \%$ of readings at range $0.05-1.00 \mathrm{~m} / \mathrm{s} . \pm 3 \%$ of readings at range $1.00-5.00 \mathrm{~m} / \mathrm{s}]$ were logged at an interval of 6 minutes at heights between 0.5 and 1.0 meter, since it was not practically possible to install all sensors at the ISO 7726:1998 [23] prescribed height of 0.6 meter. Measurement results were averaged over the morning and afternoon session. (Horizontally) Uniform conditions have been assumed for the investigated configurations. Results from [24] indicate that presence of the children enhances mixing. This may not hold true near the façade and the window openings.

Clothing insulation and metabolic rate were determined with questionnaires, which inevitably leads to an uncertainty in the results. This method was chosen to minimize the impact on the children's classroom activities. Since the aim of the research is exploratory and not much is known about clothing insulation at changing exterior temperatures for children, this method will result in new information.

Data for the exterior climate was taken from the Royal Netherlands Meteorological Institute (KNMI [25]), which was measured in Eindhoven. The daily value table was used and from the data provided the daily minimum and maximum temperatures were used, as well as the mean relative humidity.

\section{Results}

Figure 1 shows that indoor operative temperature follows the exterior running mean temperature. During winter and mid-season the interior temperature is not influenced much, but when the exterior temperature rises the indoor temperature follows this trend, rising about $0.5 \mathrm{~K}$ for each $1 \mathrm{~K}$ (4 day weighted mean) increase outside. The exterior temperatures during the seasons were within normal ranges, but the summer measurements took place during the warmest days of the year. The trend line shown is a Locally weighted scatterplot smoothing (LOESS) curve (Epanechnikov kernel, $50 \%$ fit).

The individual daily clothing insulation values are shown in Figure 2. The trend lines in this figure are also LOESS curves (Epanechnikov kernel, $50 \%$ fit), for male, female and all students together. As is to be expected, the clothing insulation shows a negative trend with increasing exterior temperatures. The decrease in clo is not constant during the year; the largest change is found during the mid-season.

Figure 3 shows the actual thermal sensation against the PMV calculated with the personal values (met*1.7/1.14 and clothing insulation from questionnaires) and mean environmental values for that part of day. Figure 4 shows the Actual Mean Vote for a part of day against PMV calculated with actual mean personal and environmental values for that part of day. In both figures a trendline is shown with corresponding $\mathrm{R}^{2}$ value. The dotted line in both figures shows Actual=Predicted, so ideally all values would be on this line. The reality is that actual (mean) sensations are mostly higher than PMV.

\section{Discussion}

What should be taken into account when evaluating the results is that they are based on a relative small sample of three classrooms (79 children) and conclusions therefore should be assessed as preliminary.

The average vote during the summer period was above +2 for two out of three schools. Since this is far away from neutral thermal sensation, results might be unreliable in these cases. Even so, the PMV method's reliability ranges stated in ISO 7730 [6] are not exceeded except for one predicted mean vote above +2 , and a few short moments where the temperature was above $30^{\circ} \mathrm{C}$. For the individual PMV calculations more predictions were above +2 .

There is a clear correlation between thermal and draught sensation votes. At higher thermal sensations the (mean) draught sensation is lower. At a thermal sensation of -3 the draught sensation is considered too high by $72 \%$ of children, but this category only consists of 29 votes. At a vote of $-2(n=36) 26 \%$ considers the draught too high. At higher thermal sensations $(-1$ to +3 ) each category has over 100 votes and less than $15 \%$ draught complaints.

The measured air speeds were very low; the mean was around $0.05 \mathrm{~m} / \mathrm{s}$, which is at its minimum detection level, in winter and showed a linear rising trend to $0.08 \mathrm{~m} / \mathrm{s}$ in summer, even though windows were opened. It is unclear whether this is caused by low outdoor air speeds, and if these air speeds occur in all schools in the Netherlands. The velocity sampling procedure may have limited the option to capture short term peaks present. Nevertheless, assuming a turbulence intensity of $30 \%$, the measurements should have been able to determine the average air speed over the morning and afternoon session with an 
inaccuracy of $\pm 10 \%$ ( $90 \%$ probability). Higher air speeds could offset high indoor air temperatures and thereby lower the mean thermal sensation. The relative air humidity was also relatively low with values from $20 \%$ to $50 \%$ year round, but still mostly within comfort limits.

Effects of air speed and body movement on the vapour resistance and thermal comfort [12] have been neglected, since the influence of skin wettedness on the thermal sensation for children is unknown.

When the total clothing ensemble specified by the children seemed incomplete or unrealistic, the data was disregarded. This was the case in $5 \%$ of the questionnaires. Determining clothing insulation of garments can lead to variations of $20 \%$ depending on the source used [11], so the values found might be different when a different source is used. The simplifications and assumptions concerning the questionnaires themselves lead to an uncertainty of about $0.1 \mathrm{clo}$, depending on the season.

There is only a small difference between male and female's clothing insulation, similar to results from a study by Humphreys [16] where clothing for 7-9 year olds in a classroom was studied. For (mean) clothing insulation for adults in office buildings, de Carli et al [26] also showed a small difference between male and female, whereas Fishman and Pimbert [27] found a large difference. The mean clothing insulation in winter is about $0.9 \mathrm{clo}$, which is comparable to values recorded by the previously mentioned sources and de Dear et al [7]. This value drops to about 0.3 clo in summer, which is slightly lower than the minimum values in the previously mentioned sources, but significantly lower than the mean in [7] and mean for males from [27] at comparable exterior temperatures. During the summer period the children mostly wore shorts, slippers and a t-shirt arriving at a total clothing insulation around 0.25-0.30 clo, whereas in office buildings this clothing ensemble is often not accepted. This means that the average clothing insulation for children can assume slightly lower values in summer than that of adults in an average office environment. The difference between male and female pupils is smaller than the corresponding standard deviations in daily clothing insulation. The standard deviation of the clothing insulation is lower in summer, similar to results presented by Corgnati et al [10].

The local regression curve for the mean clothing insulation of all children from Figure 2 can be described with three linear functions, which roughly match the winter, mid-season and summer seasons. These functions are shown in Table 2. Outside of this range for external temperatures the mean clothing insulation is unknown, but this range almost fully captures the Dutch climate.

Table 2: Multi-period linear function for children's mean clothing insulation

\begin{tabular}{ll}
\hline$\theta \mathrm{e}$, ref $\left[{ }^{\circ} \mathrm{C}\right]$ range & Linear relation \\
\hline$-3<\theta \mathrm{e}$, ref $<8 ;$ & Mean clo $=0.9-0.1 * \frac{\theta e, \text { ref }--3}{11} ;$ \\
\hline $8<\theta \mathrm{e}$, ref $<16 ;$ & Mean clo $=0.8-0.34 * \frac{\theta e, \text { ref }-8}{8} ;$ \\
\hline $16<\theta$ e, ref $<25 ;$ & Mean clo $=0.46-0.16 * \frac{\theta e, r e f-16}{9} ;$ \\
\hline
\end{tabular}

Linear regressions have been performed for both mean and individual clothing insulation, for external temperatures Tmin (daily minimum temperature), Tmean (mean of daily minimum and maximum), $\theta$ e, ref and $\theta \mathrm{rm}$. It can be seen in Table 3 that the $\mathrm{R}^{2}$ value for both clo values is highest for the linear regression with $\theta e$,ref, but the difference with Tmean and $\theta$ rm is negligible and with Tmin is small. Assuming that Tmin is equal to T6am, this is contrary to de Carli et al [26]. Here, the difference in correlation coefficients for NV buildings was largest for T6am, though still relatively small. For HVAC buildings all differences were negligible.

Table 3: Linear regression functions and $R^{2}$ values

\begin{tabular}{lllll}
\hline & Tmin & Tmean & $\theta$ e,ref & Orm \\
\hline Mean clo & $0.816-0.029^{\star}$ Tmin & $0.930-0.024^{\star}$ Tmean & $0.927-0.025^{\star} \theta$ e, ref & $0.934-0.028^{*} \theta \mathrm{rm}$ \\
& $\mathrm{R}^{2}=0.848$ & $\mathrm{R}^{2}=0.910$ & $\mathrm{R}^{2}=0.919$ & $\mathrm{R}^{2}=0.913$ \\
\hline Individual clo & $0.827-0.032^{\star} T \operatorname{Tm} i n$ & $0.942-0.025^{*}$ Tmean & $0.936-0.026^{*} \theta \mathrm{e}, \mathrm{ref}$ & $0.937-0.029^{*} \theta \mathrm{rm}$ \\
& $\mathrm{R}^{2}=0.627$ & $\mathrm{R}^{2}=0.670$ & $\mathrm{R}^{2}=0.675$ & $\mathrm{R}^{2}=0.671$ \\
\hline
\end{tabular}

As can be seen in Figure 3 and Figure 4, the analytical PMV, calculated with actual (mean) values for clothing insulation, metabolism and average air speed, underestimates the thermal sensation vote in the range 0 to +2 . This is remarkable, since most previous research which found a difference in PMV predictions found an overestimation of thermal sensation. An expectancy factor of 1 (no influence) was used; if this is changed it would only make the underestimation larger.

The largest differences occurred during the mid-season, but on average the underestimation in summer was larger. The midseason differences are exceptional cases, so the higher mean underestimation during summer is where the actual largest unreliability in the PMV prediction lies. During the summer, at $\theta$ e, ref of 15 to $25^{\circ} \mathrm{C}$, the difference is between 0.5 and 1.5 scale 
points, with a mean near 1 . The scale of this difference shows that the PMV method, using a surface-area corrected metabolic rate, does not result in valid predictions of the thermal sensation of children.

The mean metabolic rate determined from the questionnaires was 1.26 met. This value was quite constant for all schools and seasons, and did not show dependence on any of the other measured variables. When this value is multiplied by 58.2 * $1.7 / 1.14$ to take the reduced surface area of children into account this results in a mean value of $109 \mathrm{~W} / \mathrm{m}^{2}$. With this correction factor applied to the individually indicated metabolism in the PMV function, Figure 3 and Figure 4 were created. If the actual $\mathrm{W} / \mathrm{m}^{2}$ are used, estimated at $60 \mathrm{Wm}^{2}$ based on [17], the underestimation of thermal sensation by the PMV method is even larger. The heat balance of children with the thermal environment, and specifically the role of activity levels and metabolic rate in thermal sensation and thermal comfort of children, needs further research.

The temperature ranges for use of PMV stated in ISO $7730[6]$ are $10-30^{\circ} \mathrm{C}$ for air, and $10-40^{\circ} \mathrm{C}$ for radiant. Humphreys and Nicol [8] showed that discrepancies in PMV are to be expected at operative temperatures above $27^{\circ} \mathrm{C}$, but this would still only account for unreliable results for a small part of the current data.

The PMV values, calculated with the multi-period linear function for clo, a constant metabolic rate of $109 \mathrm{~W} / \mathrm{m}^{2}$, and a linear function for $\mathrm{v}$, gives results similar to the analytical PMV where actual determined values are used. The maximum difference found was 0.6 , and on average the difference was 0.17 scale points. This comparison is shown in Figure 5 . With the reliability range of about 0.5 scale points in mind, this multi-period linear function for the clo-value could be used to create comfort limits for situations where similar clothing insulation, air speeds and activity levels are to be expected, but this is not useful since the predictions themselves are not accurate.

Table 4 shows the actual percentage and amount of children dissatisfied for each thermal sensation vote and season, with corresponding total amount of children for that thermal sensation. During the winter measurements thermal acceptance was not determined. Since the PMV method is only reliable for the range -2 to +2 , the two outer categories do not show the standard PPD. These results show that the minimum of the actual percentage dissatisfied is higher than the minimum of $5 \%$ as indicated by PPD, but that the dissatisfaction at warmer thermal sensations is lower. For the cooler thermal sensations there is very few data available. The results seem to indicate an apparent difference in the relation between thermal sensation and thermal dissatisfaction for children, which needs to be investigated in further detail. Looking at the mid-season data, it can be concluded that children have a wider range of acceptable thermal sensations. An explanation may be found in the possibly incomplete understanding of the thermal sensation scale compared to the thermal acceptability. Assuming the wider range of acceptable thermal sensation as found in the mid-season data this would mean that underestimation of the PMV-value is less prominent. Summer data present a less clear possible correlation. More research is required on this part.

The percentage dissatisfied is higher for all thermal sensations in summer. During the summer season, a thermal sensation of +2 corresponds with $58 \%$ dissatisfied, where in the mid-season this is only $27 \%$. There is also more dissatisfaction for a vote of +3 in summer. The same trend that was predicted by McIntyre, cited and confirmed by Corgnati et al [10] can be seen in this. They have shown that the thermal preference in winter lies at a thermal sensation vote of about +1 and during the mid-season closer to +0 , and hypothesise a further shift towards a negative thermal sensation preference for the warm season. The explanation for this is that people in a cold climate prefer a slightly warm thermal environment, whereas persons in a hot climate prefer a slightly cool sensation. If comfort limits are created based on PMV this should be taken into account, to ensure an assessment of thermal comfort instead of thermal neutrality.

Table 4: Thermal sensation and acceptance per season

\begin{tabular}{|c|c|c|c|c|c|c|c|c|c|}
\hline Thermal sensation & & -3 & -2 & -1 & 0 & 1 & 2 & 3 & Total \\
\hline Winter & $\mathrm{n}$ & 25 & 31 & 67 & 161 & 235 & 189 & 86 & 794 \\
\hline \multirow[t]{3}{*}{ Mid-season } & $\mathrm{n}$ & 6 & 4 & 29 & 112 & 135 & 144 & 79 & 509 \\
\hline & $\mathrm{n}$ dissatisfied & 5 & 2 & 5 & 10 & 21 & 39 & 49 & 122 \\
\hline & $\%$ dissatisfied & $83 \%$ & $50 \%$ & $17 \%$ & $9 \%$ & $16 \%$ & $27 \%$ & $62 \%$ & $24 \%$ \\
\hline \multirow[t]{3}{*}{ Summer } & $\mathrm{n}$ & 0 & 1 & 9 & 51 & 115 & 282 & 405 & 863 \\
\hline & $\mathrm{n}$ dissatisfied & 0 & 1 & 3 & 14 & 29 & 164 & 344 & 555 \\
\hline & $\%$ dissatisfied & - & $100 \%$ & $33 \%$ & $27 \%$ & $25 \%$ & $58 \%$ & $85 \%$ & $64 \%$ \\
\hline Standard PPD & $\%$ dissatisfied & - & $75 \%$ & $25 \%$ & $5 \%$ & $25 \%$ & $75 \%$ & - & \\
\hline
\end{tabular}

Since the PMV assessment is not applicable for children without large-scale research on the thermal heat balance and comfort for children, other assessment methods will have to be investigated. Of the available assessment methods most are not developed for this type of building, but their building-type application range will not be discussed here. The question is whether they can be used to accurately assess children's thermal comfort. This assessment is shown in Figure 6.

Most of the measured conditions were within the ISSO 74 [1], ISSO 89 [21] and EN-15251 Annex A2 [19] outer limits, but ASHRAE standard 55 [5] is stricter in this situation. The high temperature limits for categories II and III from ISSO 89 are very tolerant at high external temperatures. EN-15251 Annex A2 uses categories which are supposed to be stricter, with only 6, 10 or $15 \%$ dissatisfied, where ISSO 74 uses 10,20 and $35 \%$ and ASHRAE 55 uses 10 and $20 \%$. In reality these limits are comparable to the ISSO 74 Alpha summer limits. For the ASHRAE and EN graphs, the situation for the heating season/static limits is shown in gray lines. Normally these are not represented in this type of graph, therefore these are not the exact prescribed limits. 
Even though nearly all measured situations would fall within the adaptive limits discussed, the mean thermal sensations show a very different picture. For example, temperatures predicted to be comfortable by ISSO 74 and other limits are actually considered warm. Only at the lowest external temperatures the mean thermal sensations are near neutral. When thermal acceptance is used the results are more comparable to the various adaptive limits since not only a neutral sensation is acceptable, but still many of the measured temperatures, within the temperature range which is assessed as comfortable by the limits, are actually considered unacceptable. Thermal acceptance was only determined in the mid-season and summer, so this data is not shown here.

The difference between actual and expected thermal satisfaction during summer can partly be explained by the low actual air speeds of below $0.1 \mathrm{~m} / \mathrm{s}$ in this period, since these adaptive methods are based on field research stating $0.3-0.4 \mathrm{~m} / \mathrm{s}$ in summer [7].

In ISSO 74 the Beta limits (dash-dot lines) are stricter for high external temperatures, and using these limits would result in a less inaccurate prediction of the children's discomfort. Children are free to adapt their clothing or posture. This assumption would favour use of the adaptive approach. However, they do not have full personal control of operable windows; these are either controlled by the teacher or by a few children. The question therefore is whether adaptive methods actually are applicable in this case.

\section{Conclusions}

The mean clothing insulation for 9-11 year old children in a primary school classroom can be described by a three-period linear function of $\theta \mathrm{e}$,ref. The mean clothing insulation changes most during the mid-season. The difference between male and female is small; the largest difference is about $0.1 \mathrm{clo}$, this occurs at a $\theta$ e, ref of $-3^{\circ} \mathrm{C}$. The mean changes from $0.9 \mathrm{clo}$ at $\theta e$, ref $=-3^{\circ} \mathrm{C}$; to 0.8 clo at $8^{\circ} \mathrm{C} ; 0.46$ clo at $16^{\circ} \mathrm{C}$; and 0.3 clo at $25^{\circ} \mathrm{C}$.

From the obtained results for this small group $(n=79)$ it can be concluded that the PMV method underestimates thermal sensation for children, while most previous research which found errors in PMV predictions found that it overestimated thermal sensation. The error is largest in summer, with underestimation ranging from 0.5 to 1.5 scale points at $\theta e$, ref of 15 to $25^{\circ} \mathrm{C}$. For these results the metabolism was estimated by using adult's data corrected for reduced body surface area. This results in an average of $109 \mathrm{~W} / \mathrm{m}^{2}$ in this research, which is higher than for an adult in sedentary activity $\left(70 \mathrm{~W} / \mathrm{m}^{2}\right)$, but as indicated the resulting PMV is still lower than actual thermal sensation. The metabolism in actual W/m², which can be estimated at $60 \mathrm{~W} / \mathrm{m}^{2}$ for 9-11 year old children in sedentary classroom activities based on research by Havenith [17], results in a lower PMV so an even larger underestimation in predictions. This shows that the PMV method cannot be applied to children in a classroom situation and that PMV with surface area-corrected metabolism is better but still does not result in valid predictions of the thermal sensation of these children.

The actual thermal sensation does not support use of current adaptive thermal comfort assessment methods. Similar to the PMV predictions, these adaptive limits underestimate the thermal sensation and predict higher comfortable temperatures than those actually indicated by the children. This means that the currently applied assessment methods for primary schools are not correct, and complying with these demands does not necessarily lead to a comfortable situation for children. To improve children's thermal comfort, indoor air temperatures in primary school classrooms should be kept a few degrees below the limits for office buildings, but exact limits cannot be predicted based on this research.

More research is needed on the subject of thermal comfort of children, since the assessment methods for adults do not seem applicable. This is the case for assessment by PMV and also for adaptive limits. For PMV the role of metabolism in the heat balance and comfort of children needs evaluation, since the physiological basis of the method is that of adults and the relations between metabolism, surface temperature, sweating etc. and thermal sensation and comfort are different for children. The conception of thermal sensation compared to thermal comfort by children is a research topic that should be included as well. In that case, questions on thermal sensation, thermal preference and thermal satisfaction should be considered by applying a continuous scale.

If PMV based comfort limits are to be created, these should take into account the seasonal influences on thermal preference. For this, more research on thermal sensation and thermal preference in various seasons or climates is needed.

\section{Acknowledgements}

This research would not have been possible without the cooperation of the three schools, and the valuable input of the teachers and children in the classes. Michael Humphreys is acknowledged for the helpful email correspondence.

\section{References}

1. ISSO. ISSO Publicatie 74; Thermische behaaglijkheid - eisen voor de binnentemperatuur in gebouwen. Rotterdam : Stichting ISSO, 2004.

2. Fanger, P.O. Thermal Comfort: analysis and applications in environmental engineering. Copenhagen : Danish Technical Press, 1970. 
3. van der Linden, W., Loomans, M. and Hensen, J. Adaptive thermal comfort explained by PMV. Proceedings of the $11^{\text {th }}$ International Conference on Indoor Air Quality and Climate, Indoor Air, 17-22 August, P. Strøm-Tejsen et al., eds.,Copenhagen. 2008, p.8 on CD. Paper ID: 573.

4. Boerstra, A. and van Dijken, F. Indoor environment and energy efficiency of schools. REHVA journal. September 2010, 19.

5. ASHRAE. ANSI/ASHRAE Standard 55-2004 Thermal Environmental Conditions for Human Occupancy. Atlanta : American Society of Heating, Refrigirating and Air-Conditioning Engineers, 2004. ISSN 1041-2336.

6. ISO. EN ISO 7730:2005 Ergonomics of the thermal environment - Analytical determination and interpretation of thermal comfort using calculation of the PMV and PPD indices and local thermal comfort criteria. Geneva : International Standardisation Organisation, 2005.

7. de Dear, R., Brager, G. and Cooper, D. Developing an Adaptive Model of Thermal Comfort and Preference. 1997. Final Report ASHRAE RP-884.

8. Humphreys, M.A. and Nicol, J.F. The validity of ISO-PMV for predicting comfort votes in every-day thermal environments. Energy and Buildings. 2002, Vol. 34, pp. 667-84.

9. van Hoof, J. Forty years of Fanger's model of thermal comfort: thermal comfort for all? Indoor Air. 2008, 18, pp. 182-201.

10. Corgnati, S. P., Ansaldi, R. and Filippi, M. Thermal comfort in Italian classrooms under free running conditions during mid seasons: Assessment through objective and subjective approaches. Building and Environment. 2008. doi:10.1016/j.buildenv.2008.05.023.

11. Brager, G., Fountain, M., Benton, C., Arens, E.A. and Bauman, F. A Comparison of Methods for Assessing Thermal Sensation and Acceptability in the Field. Indoor Environmental Quality (IEQ), Center for the Built Environment, Center for Environmental Design Research, UC Berkeley. 1993.

12. Havenith, G., Holmér, I. and Parsons, K. Personal factors in thermal comfort assessment: clothing properties and metabolic heat production. Energy and Buildings. 2002, 34, pp. 581-91.

13. ISO. EN ISO 8996:2004 Ergonomics of the thermal environment - Determination of metabolic rate. Geneva : International Standardisation Organisation, 2004.

14. Yao, R., Li, B. and Liu, J. A theoretical adaptive model of thermal comfort - Adaptive Predicted Mean Vote (aPMV). Building and Environment. 2009, 44, pp. 2089-96.

15. Fanger, P.O. and Toftum, J. Extension of the PMV model to non-air-conditioned buildings in warm climates. Energy and Buildings. 2002, 34, pp. 533-66.

16. Humphreys, M.A. A Study of the Thermal Comfort of Primary School Children in Summer. Building and Environment. 1977, 12, pp. 231-9.

17. Havenith, G. Metabolic rate and clothing insulation data of children and adolescents during various school activities. Ergonomics. 2007, Vol. 50, 10, pp. 1689-701.

18. Parsons, K.C. Human thermal environments: the effects of hot, moderate and cold environments on human health, comfort and performance. 2nd Edition. London : Taylor and Francis, 2001.

19. CEN. EN 15251:2007 Indoor environmental input parameters for design and assessment of energy performance of buildings addressing indoor air quality, thermal environment, lighting and acoustics. Brussels : European Committee for Standardization, 2007.

20. Nicol, F. and Humphreys, M. Derivation of the adaptive equations for thermal comfort in free-running buildings in European standard EN15251. Building and Environment. 2010, 45, pp. 11-7.

21. ISSO. ISSO Publicatie 89; Binnenklimaat scholen. Rotterdam : Stichting ISSO, 2008.

22. Mosteller, R.D. Simplified calculation of body-surface area. The New England Journal of Medicine. 1987, 317:1098.

23. ISO. EN ISO $7726: 1998$ Ergonomics of the thermal environment - Instruments for measuring physical quantities. Geneva : International Standardisation Organisation, 1998.

24. Karimipanah, T., Sandberg, S and Awbi, H.B. A comparative study of different air distribution systems in a class room. Reading, UK : In: Proceedings ROOMVENT 2000, 2000, Vol. Vol.2. pp. 1013-1018. 
25. KNMI. Daggegevens van het weer in Nederland: 370 - Eindhoven. Royal Netherlands Meteorological Institute. [Online] Ministry of Infrastructure and the Environment, 2010. [www.knmi.nl/klimatologie/daggegevens/download.html; last accessed: 14 10 2010]

26. De Carli, M., Olesen, B.W., Zarrella, A. and Zecchin, R. People's clothing behaviour according to external weather and indoor environment. Building and Environment. 2007, 42, pp. 3965-73.

27. Fishman, D.S. and Pimbert, S.L. The Thermal Environment in Offices. Energy and Buildings. 1982, 5, pp. 109-16. 
Table 1: Variables to define external climate as used in various standards

\begin{tabular}{lll}
\hline Standard & $\begin{array}{l}\text { Exterior } \\
\text { Temperature } \\
\text { variable }\end{array}$ & Definition \\
\hline ASHRAE 55-1992 & ET $^{*}$ & Mean daily outdoor effective temperature \\
\hline ASHRAE 55-2004 & $\mathrm{t}_{\mathrm{a}(\mathrm{out})}$ & Monthly mean of daily min/max mean \\
\hline NEN-EN 15251 & $\theta_{\mathrm{rm}}$ & Weighted running mean of daily mean, excluding current day \\
\hline ISSO 74 & $\theta_{\mathrm{e}, \text { ref }}$ & 4 day weighted running mean of daily min/max mean, including current day \\
\hline ISSO 89 & $\theta_{b u}$ & Current external temperature \\
\hline
\end{tabular}

Table 2: Multi-period linear function for children's mean clothing insulation

\begin{tabular}{ll}
\hline$\theta$ e,ref $\left[{ }^{\circ} \mathrm{C}\right]$ range & Linear relation \\
\hline$-3<\theta$ e, ref $<8 ;$ & Mean clo $=0.9-0.1 * \frac{\theta e, \text { ref }--3}{11} ;$ \\
\hline $8<\theta$ e, ref $<16 ;$ & Mean clo $=0.8-0.34 * \frac{\theta e, r e f-8}{8} ;$ \\
\hline $16<\theta$ e, ref $<25 ;$ & Mean clo $=0.46-0.16 * \frac{\theta e, r e f-16}{9} ;$ \\
\hline
\end{tabular}

Table 3: Linear regression functions and $\mathrm{R}^{2}$ values

\begin{tabular}{|c|c|c|c|c|}
\hline & Tmin & Tmean & $\theta e$, ref & $\theta \mathrm{rm}$ \\
\hline Mean clo & $\begin{array}{l}0.816-0.029 * T \min \\
\mathrm{R}^{2}=0.848\end{array}$ & $\begin{array}{l}0.930-0.024^{*} \text { Tmean } \\
\mathrm{R}^{2}=0.910\end{array}$ & $\begin{array}{l}0.927-0.025^{\star} \theta e, \text { ref } \\
R^{2}=0.919\end{array}$ & $\begin{array}{l}0.934-0.028^{*} \theta \mathrm{rm} \\
\mathrm{R}^{2}=0.913\end{array}$ \\
\hline Individual clo & $\begin{array}{l}0.827-0.032 * T \min \\
\mathrm{R}^{2}=0.627\end{array}$ & $\begin{array}{l}0.942-0.025^{*} \text { Tmean } \\
\mathrm{R}^{2}=0.670\end{array}$ & $\begin{array}{l}0.936-0.026^{*} \theta e, \text { ref } \\
R^{2}=0.675\end{array}$ & $\begin{array}{l}0.937-0.029^{*} \theta \mathrm{rm} \\
\mathrm{R}^{2}=0.671\end{array}$ \\
\hline
\end{tabular}

Table 4: Thermal sensation and acceptance per season

\begin{tabular}{|c|c|c|c|c|c|c|c|c|c|}
\hline Thermal sensation & & -3 & -2 & -1 & 0 & 1 & 2 & 3 & Total \\
\hline Winter & $\mathrm{n}$ & 25 & 31 & 67 & 161 & 235 & 189 & 86 & 794 \\
\hline \multirow[t]{3}{*}{ Mid-season } & $\mathrm{n}$ & 6 & 4 & 29 & 112 & 135 & 144 & 79 & 509 \\
\hline & n dissatisfied & 5 & 2 & 5 & 10 & 21 & 39 & 49 & 122 \\
\hline & $\%$ dissatisfied & $83 \%$ & $50 \%$ & $17 \%$ & $9 \%$ & $16 \%$ & $27 \%$ & $62 \%$ & $24 \%$ \\
\hline \multirow[t]{3}{*}{ Summer } & $\mathrm{n}$ & 0 & 1 & 9 & 51 & 115 & 282 & 405 & 863 \\
\hline & n dissatisfied & 0 & 1 & 3 & 14 & 29 & 164 & 344 & 555 \\
\hline & $\%$ dissatisfied & - & $100 \%$ & $33 \%$ & $27 \%$ & $25 \%$ & $58 \%$ & $85 \%$ & $64 \%$ \\
\hline Standard PPD & $\%$ dissatisfied & - & $75 \%$ & $25 \%$ & $5 \%$ & $25 \%$ & $75 \%$ & - & \\
\hline
\end{tabular}


Figure 1: Operative temperature and exterior climate in the form of $\vartheta$ e, ref; LOESS curve (Epanechnikov kernel, 50\% fit).

Figure 2: Individual clothing insulation for male and female children against $\vartheta$ e, ref.

Figure 3: Thermal sensation and individual PMV.

Figure 4: Actual mean vote and PMV.

Figure 5: Comparison of analytical PMV and adaptive PMV.

Figure 6: Operative temperatures and adaptive assessment methods, with actual thermal sensation. 
Click here to download high resolution image

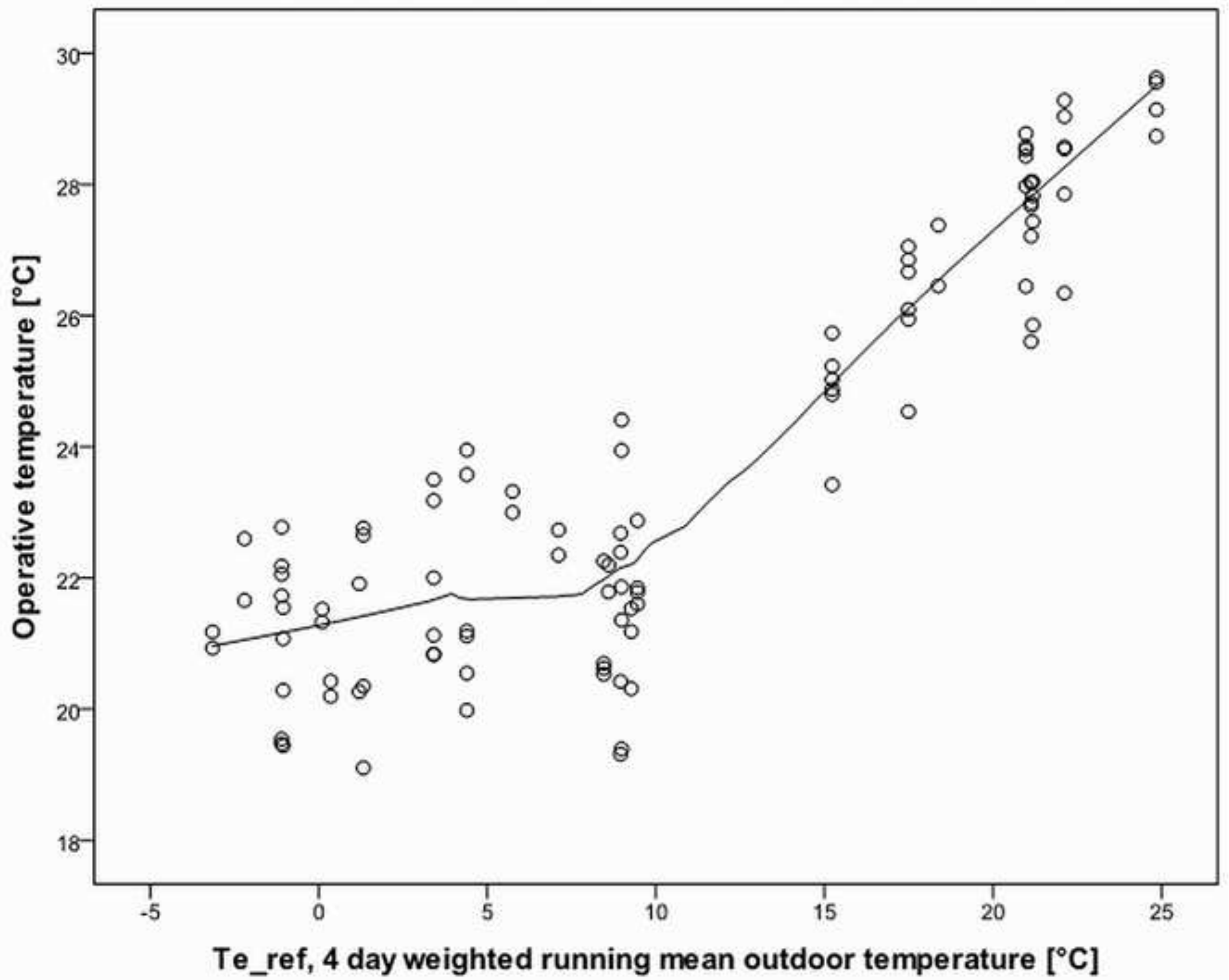




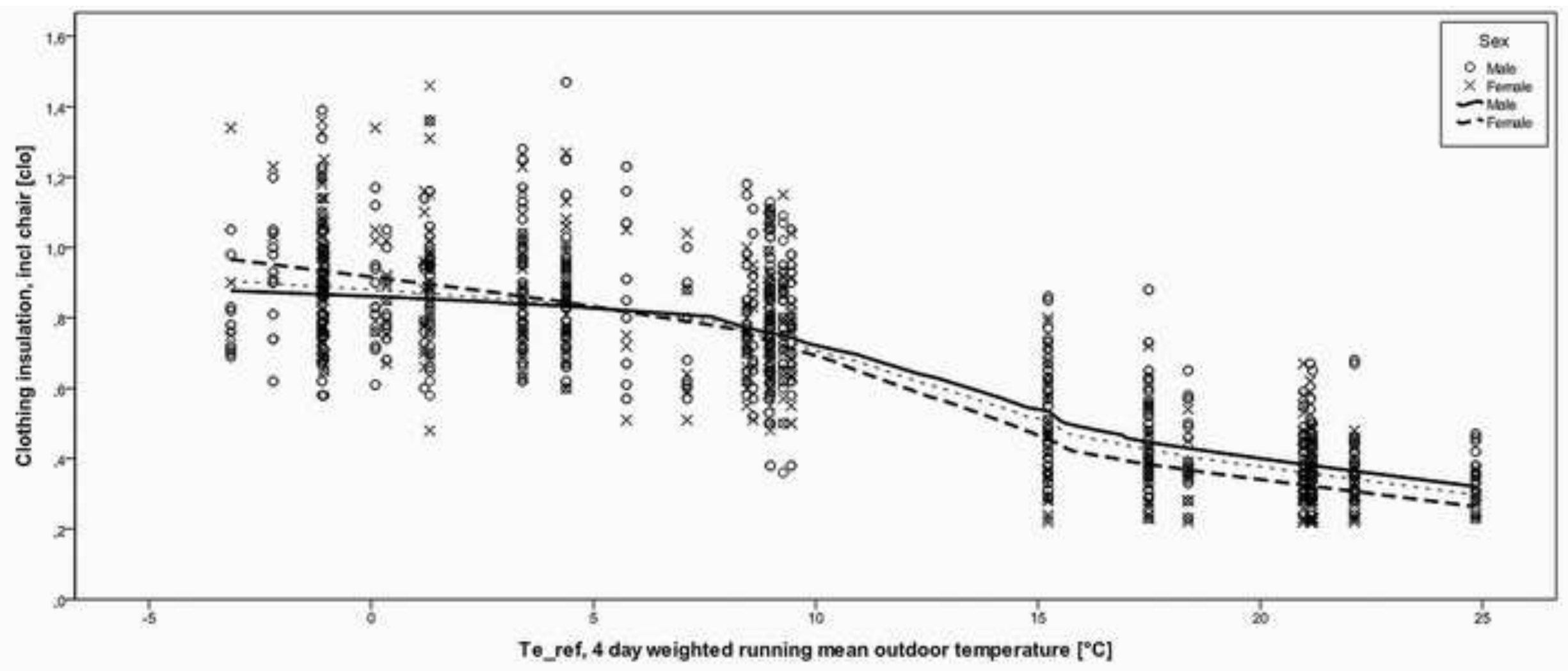


Figure 3
Click here to download high resolution image

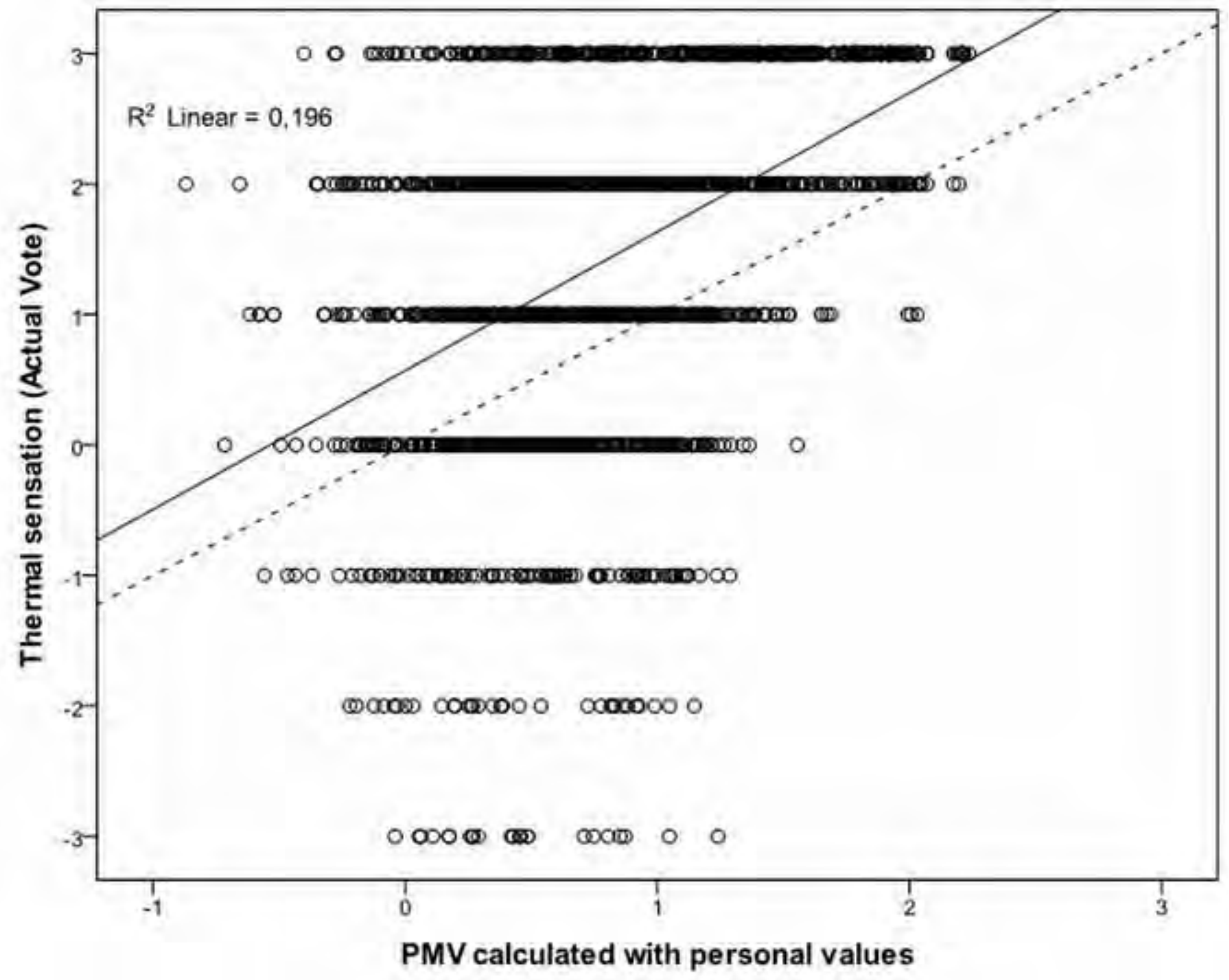


Click here to download high resolution image

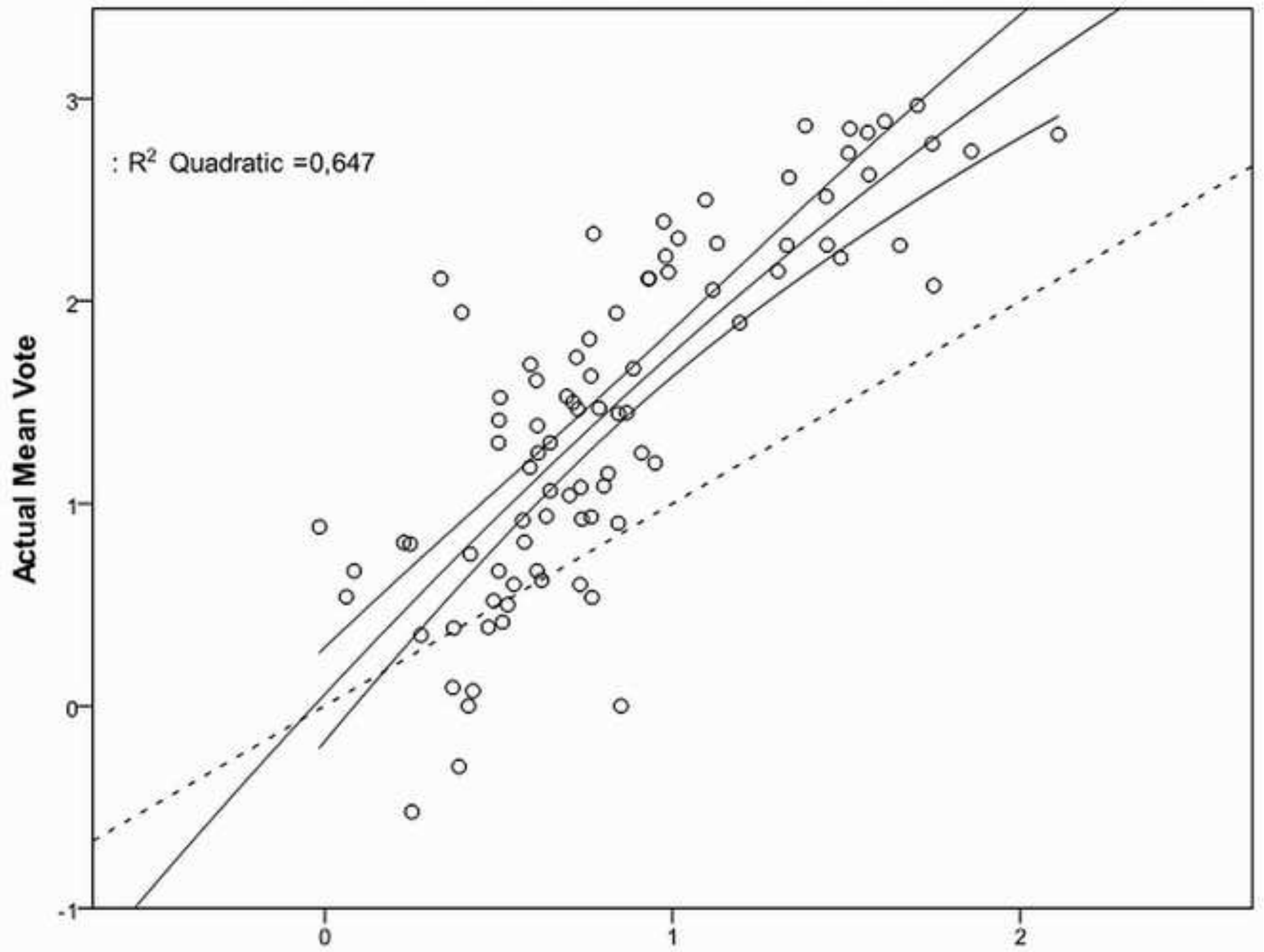

PMV calculated with mean metabolism and mean clo per part of day 
Click here to download high resolution image

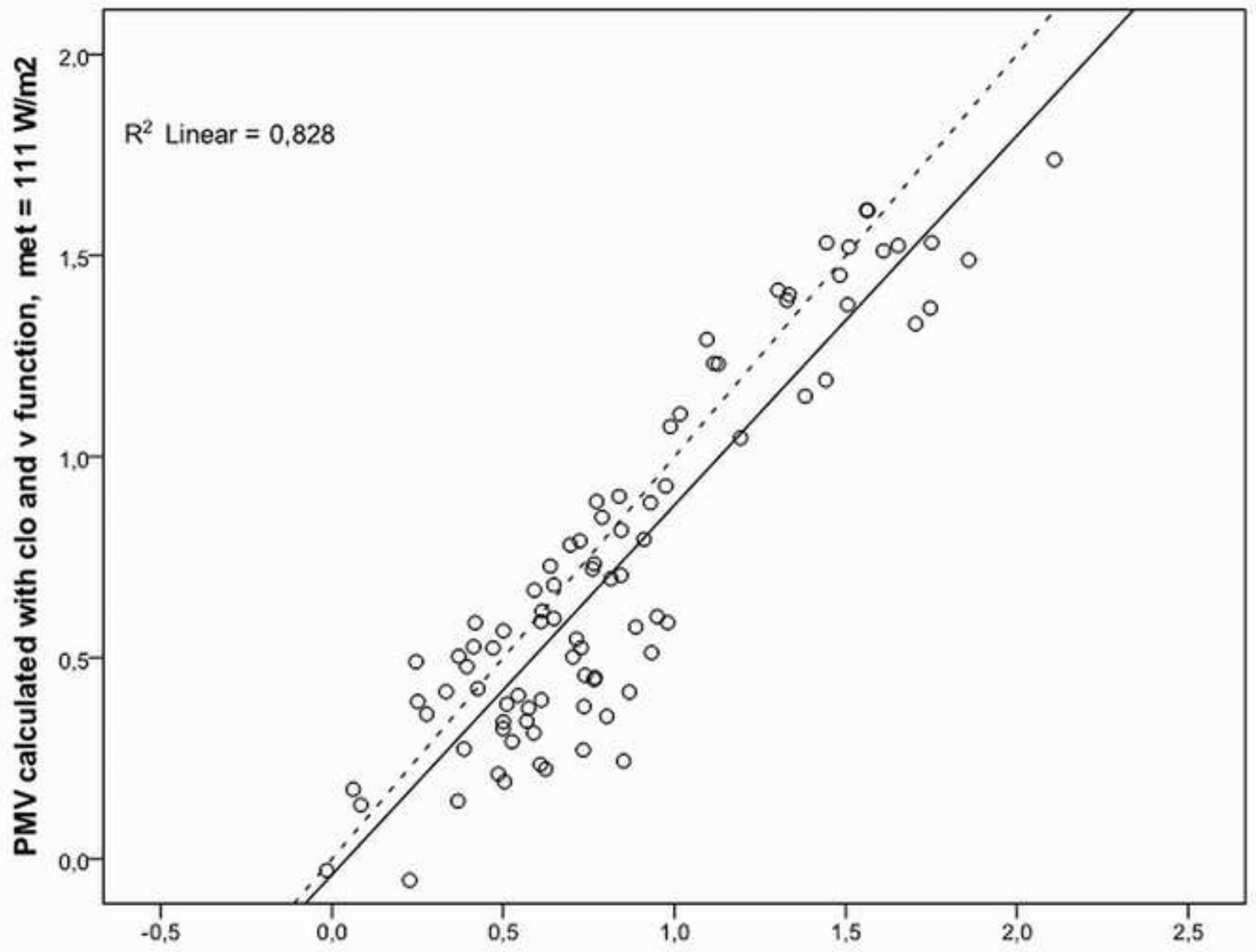

PMV calculated with mean values for metabolism, clo and v, per part of day 


\section{Figure 6a}

Click here to download high resolution image

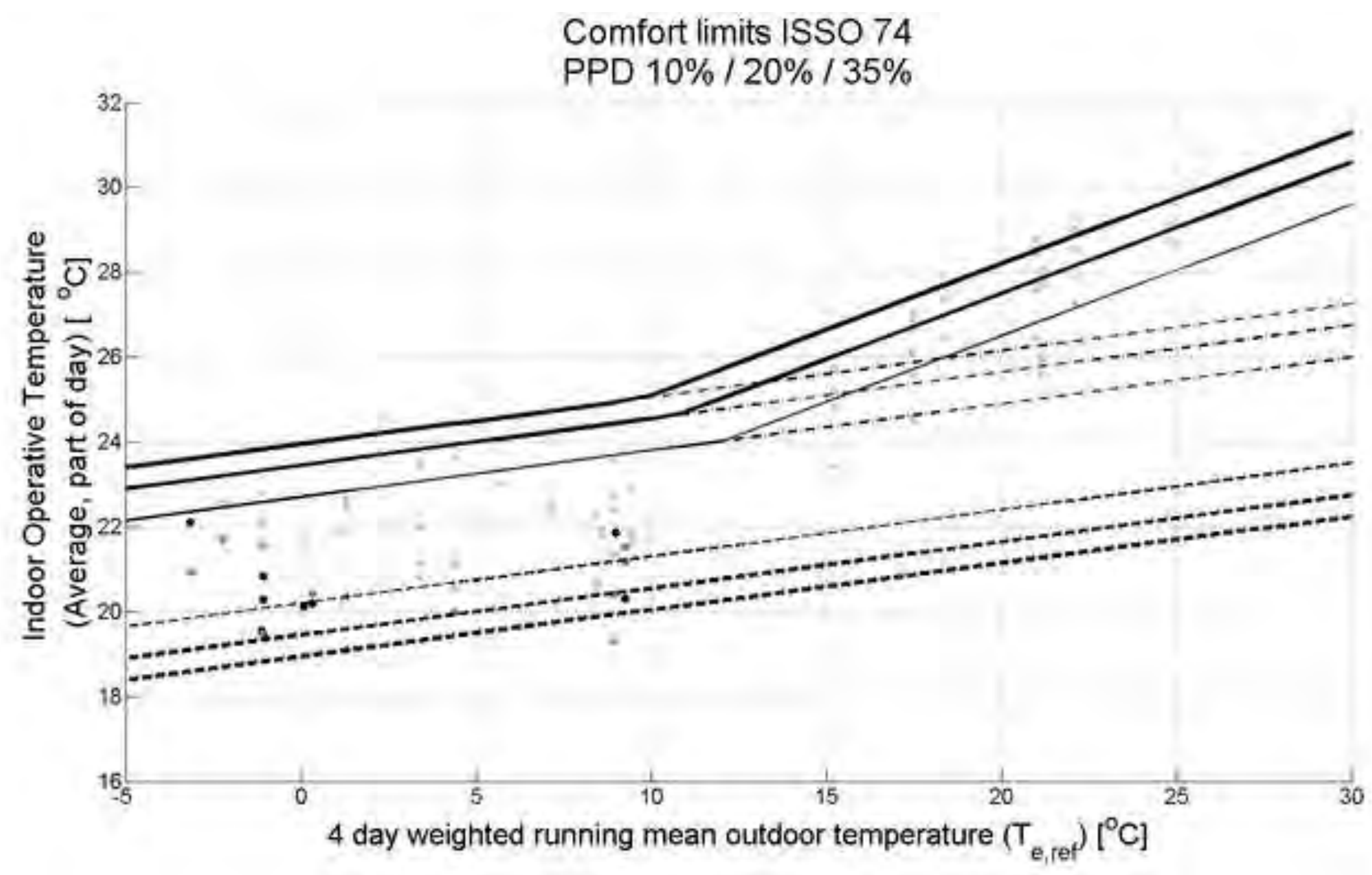

Comfort limits ISSO 74

PPD $10 \% / 20 \% / 35 \%$ 
Comfort limits ISSO 89

high / average / low expectactions (+-legal minimum)

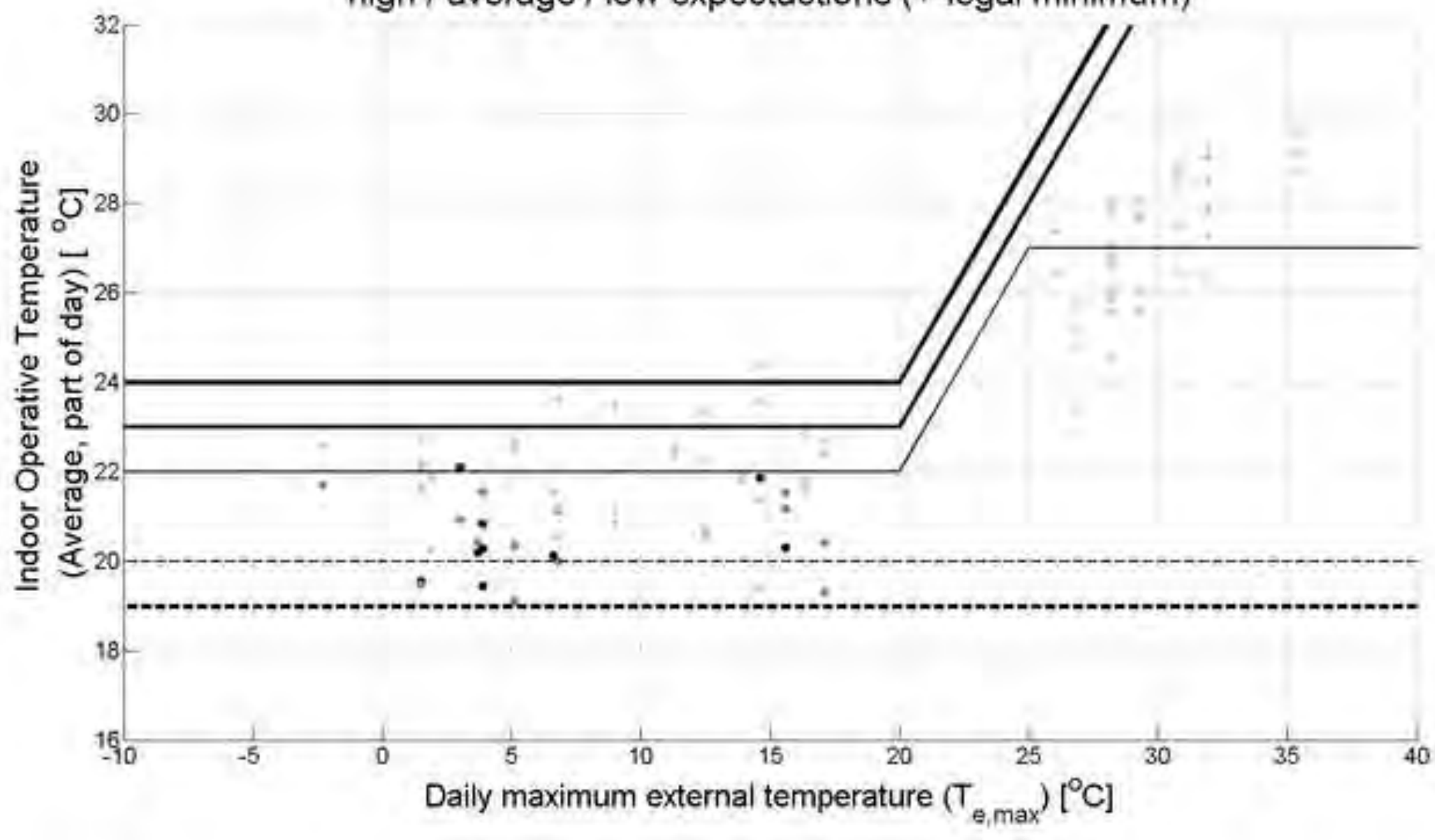




\section{Comfort limits ASHRAE 55}

PPD $10 \% / 20 \%$

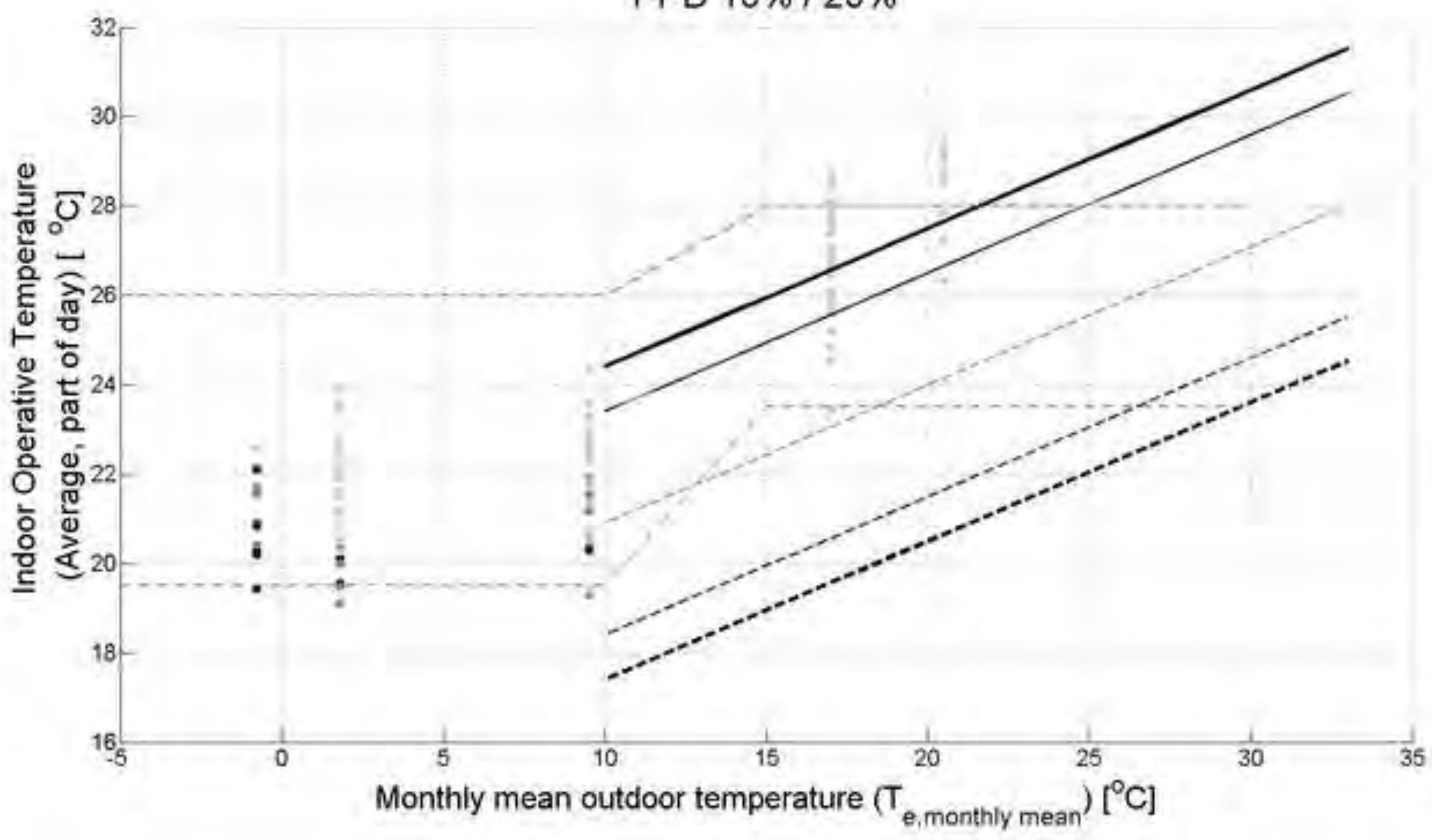




\section{Comfort limits NEN-EN 15251}

PPD $6 \% / 10 \% / 15 \%$

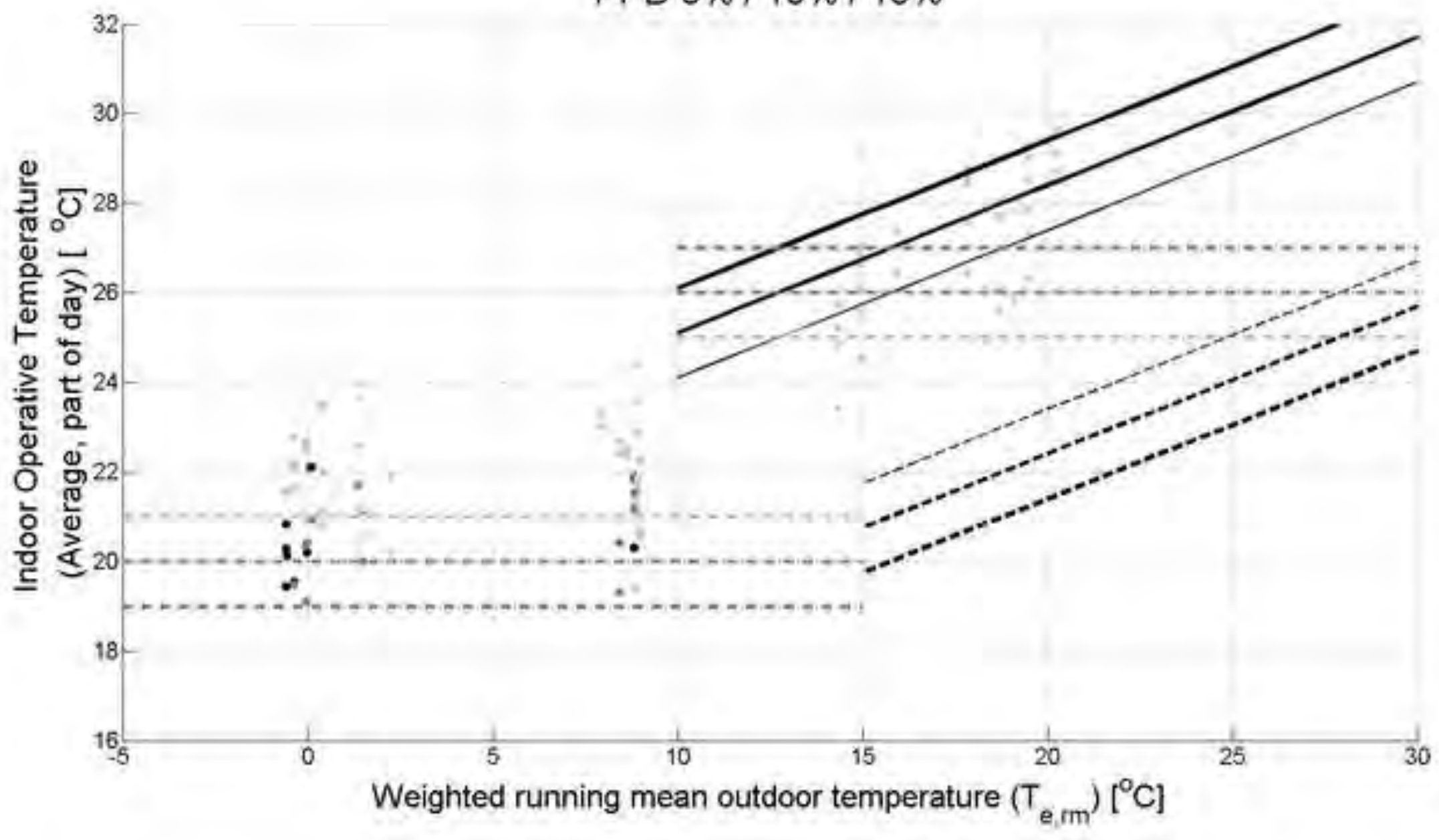




\title{
PPD from AMV$$
\text { PPD from AMV }
$$

\section{PPD $<10 \%$}

\section{$10 \%<P P D$
$20 \%<P P D$}
$10 \%<\mathrm{PPD}<20 \%$
$0 \%$

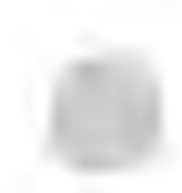

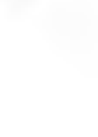

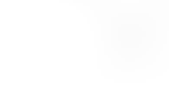

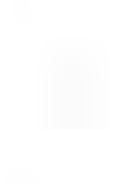

.

(1)

Click here to download high resolution imag

\begin{abstract}
$10 \%$
\end{abstract}

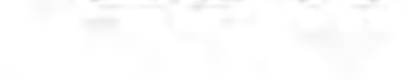

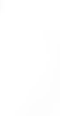

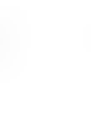

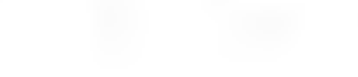

